\title{
Contents of the Following Issues of Opticheskiu Zhurnal (Journal of Optical Technology)
}

PACS numbers: 01.10.Cr

DOI: $10.1134 / \mathrm{S} 0030400 \mathrm{X} 08010232$

The following papers will be published in the January issue of Opticheskiŭ Zhurnal (Journal of Optical Technology), vol. 75, no. 1, 2008.

Physical Optics. Fiber Optic End-on Interferometer as a Versatile Tool for Design of Displacement Sensors (A.A. Vetrov, S.S. Komissarov, and A.N. Sergushichev); Fourier Transform IR Spectroscopic Study of a Mechanism of the Vapor-Phase Extraction of a Transition Metal Impurity from Aqueous Solutions (V.N. Bekhterev, A.N. Bekhterev, and V.M. Zolotarev).

Laser Physics and Technology. Nonlinear Phenomena in Doped Optic Fibers (E.Z. Savin, N.G. Osipova, and A.I. Livashvili).

Computation, Design, and Manufacture of Optical Systems. Detection of Moire Fringes during Adjusting an Interferometer to an Infinitely Wide Fringe (A.V. Bagrov, A.G. Seregin, G.N. Vinogradova, K.V. Ulitin, and I.V. Golov); Optimization of a TV Luminescent Object Visualization System Using Computer Simulation Technique (N.P. Kornyshev and A.V. Timofeev).

Iconics: The Science of Images. Modern Methods for Measuring Resolution of a Visual System
(S.A. Koskin, É.V. Boĭko, and Yu.E. Shelepin); Simulation of Thermal Images of Ground-Based Objects (V.D. Mochalin).

Optical Instrumentation and Technology. A Fluorescence Video Dermatoscope (Kang Uk, G.V. Papayan, Be Su-Jin, V.B. Berezin, and S. Kim); Estimate of the Measurement Range of a TV Monochromatic Pyrometer (A.V. Kuznetsov).

Optical Materials Science and Technology. Optical Properties of Vanadium Dioxide Nanoparticles in Nanoporous Glasses (A.I. Sidorov, O.P. Vinogradova, T.A. Khrusheva, I.E. Obyknovennaya, G.N. Ermolaeva, and V.B. Shilov); Mechanism of Passive YAG: $\mathrm{V}^{3+}$ Laser Q-Switch Bleaching during Stimulated Raman Scattering Conversion in KGW: $\mathrm{Nd}^{3+}$ Crystals (A.N. Titov, V.N. Ivanov, V.N. Vetrov, B.A. Ignatenkov, O.B. Storoshchuk, L.I. Krutova, K.V. Dukel'skiǔ, V.V. Medovolkin, E.V. Urbanovich, and D.V. Ivanov); Estimate of the Parallax of a Meniscus Image of a Growing Crystal (S.V. Mikhlyaev).

Compiled by L. V. Enushevskaya Translated by S. Belov 